\title{
MODELOS DE JUSTICIA PENAL JUVENIL EN DEBATE A INICIOS DEL SIGLO XXI
}

\section{Carolina González Laurino ${ }^{1}$}

\section{Resumen}

El artículo plantea un recorrido por los modelos de justicia juvenil desarrollados a lo largo de la historia del pensamiento contemporáneo para centrar la mirada en el sistema de responsabilidad promovido por los organismos internacionales y el debate en torno a la alternativa planteada por la justicia restaurativa.

Mediante un análisis comparativo se revisan las modificaciones de carácter represivo procesadas en los últimos años en las legislaciones española y uruguaya implementadas después de su adecuación a los tratados internacionales suscriptos por ambos países a comienzos de siglo.

Atender al debate que se plantea en torno al modelo de justicia restaurativa como alternativa a la judicialización de los integrantes más jóvenes de la sociedad supone cuidar un tipo de práctica limitada a las trasgresiones menores de los adolescentes, que podría suponer la extensión del sistema de control social a acciones que no serían punibles en el modelo justicia penal juvenil que sugieren los organismos internacionales rectores en lamateria.

Palabras clave: modelos de justicia juvenil, responsabilidad, infancia, adolescencia, justicia restaurativa.

\section{INTRODUCCIÓN}

Este artículo pretende ser un aporte a la reflexión en relación al pensamiento social de los modelos de justicia juvenil desarrollados en la historia de la represión de la infracción adolescente a la ley penal en Europa y Latinoamérica, con especial énfasis en la traslación acrítica de modelos importados desde Estados Unidos a inicios del siglo XX. Con el aporte de la bibliografía especializada, se recorren los modelos que han operado en las políticas de represión de la infracción a la adolescencia, partiendo de la construcción del sistema especializado en justicia juvenil en los tribunales de menores de Illinois en 1989, hasta las nuevas tendencias hacia la mediación en los procesos juveniles, que han sido progresivamente incorporados a las legislaciones nacionales o constituyen experiencias de desjudicialización, buscando que el adolescente no ingrese tempranamente al sistemapenal.

\footnotetext{
${ }^{1}$ Doctora en Sociología y Ciencias Políticas (opción Sociología) por la Universidad de Deusto, España. Licenciada en Sociología egresada de la Universidad de la República (Udelar). Licenciada en Trabajo Social por la Udelar. Docente e investigadora del Departamento de Trabajo Social de la Facultad de Ciencias Sociales de la Udelar. Responsable del Programa de estudio sobre control socio jurídico de infancia y adolescencia en Uruguay. Estudios sobre infracción adolescente financiado por la Comisión Sectorial de Investigación Científica (CSIC) de la Udelar. Investigadora activa del Sistema Nacional de Investigadores (SNI) de la Agencia Nacional de Investigación e Innovación (ANII).E-mail:carolsoc@gmail.com
} 
Se intenta recoger el debate abierto por el modelo de justicia restaurativa, que incorpora la figura de la víctima en el proceso penal, tanto en adultos como en adolescentes, considerado por algunos como respuesta positiva al conflicto generado por los actos socialmente reprobables, y por otros, como una mutación de carácter regresivo y conservador del modelo de inquisición pública con tendencia privatizadora.

Partiendo de una caracterización genérica, se centra posteriormente en el análisis en las transformaciones legislativas operadas en España y en Uruguay a partir de la incorporación de las recomendaciones internacionales en la materia en los primeros quince años del siglo XXI, que se construyen como respuestas a las demandas políticas y sociales de punición enfocadas en este sector de la población más vulnerable y por tanto más necesitado de protección pública.

Es necesario precisar que el texto no consiste en un aporte desde el punto de vista jurídico. Si bien parte de la información especializada en esta materia, se trata de analizar la dimensión social del fenómeno del castigo a la trasgresión en tempranas etapas de la vida con su apuesta moralizante y reformadora de la conducta adolescente.

\section{EL DERECHO PENAL JUVENIL: DEL MODELO TUTELAR A LA JUSTICIA RESTAURATIVA}

Como explica Silvia Guemureman, "la ausencia de investigaciones sobre el campo sociojurídico de la niñez y la adolescencia no puede ser desvinculada de la propia minorización que sufrieron la infancia y la adolescencia como temas con entidad propia” (2015:20).

El campo disciplinario de la infancia y la adolescencia ha ingresado en las currículas académicas de las universidades hace muy poco tiempo, guardando esta demora una correspondencia con "el descubrimiento de la infancia" (Aries 1981; Demause 1973; Donzelot 1979). La entrada de la infancia en la escena académica ha sido relativamente reciente y la mayor atención prestada a ésta se dio una vez que la cuestión de la infancia y sus derechos se instaló exitosamente en la agenda pública (García Méndez - Beloff 1998 y 2004) (GUEMUREMAN, 2015:20).

En el periplo de construcción de la categoría infancia en Occidente, el derecho penal ha sido parte de la historia del control de la infancia no normalizada por la familia y la escuela que se ha denominado justicia de menores (BELOFF, 1994; GARCÍA MÉNDEZ, 1994). Estos niños y adolescentes no disciplinados por las instituciones normalizadoras fueron objeto de la mirada compasiva y represiva del movimiento de los "Salvadores del niño" en Estados Unidos, más preocupados por su control social que por su inclusión a la vida compartida (PLATT, 1982).

Como ha sido extensamente documentado, la justicia de menores se inició en Estados Unidos, con la Illinois Juvenile Court Law de 1889, que crea los primeros tribunales especializados, posteriormente exportados a Europa (THERBORN, 1993; GONZÁLEZ TASCÓN, 2010) y a América Latina (GARCÍA MÉNDEZ, 1994, 
BELOFF, 1994). En Europa, la legislación comparada de los primeros años del siglo XX registra la creación de codificaciones legislativas en esta materia a partir del Penal Children’s Act en los Países Bajos en 1901, del Children Acten Gran Bretaña en 1905, en Portugal con la Ley de Protecçao á Infa ncia de 1911, en Bélgica con la Loisurla protection del'enfance de 1912, en Francia mediante la Loisur les tribunaux pour enfants et adolescents et sur la libertè surveillèe de 1912, en España a través de la Ley sobre organización y atribuciones de los tribunales para niños de 1918, o en Alemania mediante la Reichsjudendgerichtsgesetz de 1923 (GONZÁLEZ TASCÓN, 2010; CABEZAS SALMERÓN, 2011). En América Latina, el estudio comparado muestra codificaciones legislativas que empiezan con la creación de la Ley Agote en Argentina en 1919 y continúan este modelo de creación de tribunales judiciales para la infancia socialmente vulnerable, objeto de preocupación para la medicina y para el derecho en Brasil (1927), Costa Rica (1932), Uruguay (1934), Ecuador (1938) y Venezuela en 1939 (GARCÍA MÉNDEZ, 1994; DÁVILA y NAYA, 2010).

Estas instituciones judiciales están íntimamente ligadas a las instituciones asilares de finales del siglo XIX y principios del siglo XX que recogían, primero en instituciones religiosas y luego en sus dispositivos secularizados, a la infancia objeto de compasión-represión en una continuidad conceptualizada entre el abandono y la delincuencia que funcionaron tanto en Europa como en América Latina (LEOPOLD COSTÁBILE, 2013; DAROQUIy LÓPEZ, 2012)

Tanto en Estados Unidos como en Europa el modelo tutelar se sostiene en el positivismo criminológico y el correccionalismo, basado en un modelo determinista del comportamiento humano que explica la trasgresión por causas biológicas y sociales considerando a los infractores como "enfermos, incapaces o anormales" (GONZÁLEZ TASCÓN, 2010: 123). La autora contextualiza este modelo de pensamiento en la preocupación suscitada por las consecuencias sociales de la revolución industrial en un sistema de desprotección de derechos sociales para las clases trabajadoras.

Como indica García Méndez en alusión a Latinoamérica, las argumentaciones médicas fueron modificándose desde la fundamentación positivista antropológica de la degeneración de los hijos de los trabajadores y los excluidos hasta su sustitución por una explicación sociológica fundada en la planificación social que veía en el producto de la pobreza la distancia que la separaba de la familia nuclear patriarcal, indicando el riesgo social en las familias monoparentales con mujeres a cargo y sus productos disfuncionales en el orden de las relaciones sociales a lo que se suma la falta de incorporación a las políticas sanitarias y educativas (1994).2

\footnotetext{
${ }^{2}$ No obstante, el autor da cuenta del correlato entre la crisis de los años 30, que aumentó la desprotección de la infancia y las políticas redistributivas de los años 50 que disminuyeron el número de menores desprotegidos por el Estado en América Latina con la vuelta al modelo represivo del autoritarismo de los años 70 con disminución de las políticas asistenciales universales a cargo del Estado (García Méndez, 1994) Gustavo De Armas documenta la peripecia de las políticas de protección a la infancia en Uruguay considerando los problemas de desarrollo estructural del Uruguay en los últimos cincuenta años y sus consecuencias sociales recogiendo mediciones de índices de pobreza del Instituto Nacional de Estadística, estudios de historia económica, _vol.09, nº. 02, Rio de Janeiro, 2016. pp. 652-669 
Como en Estados Unidos y Europa, la doctrina tutelar en América Latina se caracterizó por la judicialización de los problemas sociales relacionados con la infancia otorgando poder discrecional a los jueces en una intervención de carácter tutelar sin garantías procesales para este sector de la población vulnerable. La tutela que el juez ejerce como "buen padre de familia" con argumentos de protección a la infancia desvalida parece ajustarse a los mecanismos de defensa social de los que el derecho penal dispone para conservar el estado de orden y paz social en desmedro de un progresivo deterioro de los problemas de desigualdad social en los países latinoamericanos (GARCÍA MÉNDEZ, 1994).

Aunque los autores latinoamericanos no diferencian el nacimiento del modelo de la rehabilitación o de la educación del paradigma tutelar, González Tascón junto con otros criminólogos norteamericanos y europeos dedicados al sistema penal de adultos (GARLAND y SPARKS, 2000; GARLAND, 2006; CORNELLI, 2012) lo sitúan en el marco de la expansión económica europea posterior a la II Guerra Mundial y al nacimiento de los Estados de bienestar. En este contexto la argumentación de la medicina, la psicología y la criminología revelan el carácter episódico de la trasgresión adolescente que atribuyen a déficits educativos proponiendo la desjudicialización de los asuntos relativos a la infancia y la adolescencia y la internación como último recurso. Este modelo, que involucra activamente a los servicios sociales, se comporta de la misma manera que el modelo tutelar en la indiferenciación del abandono y la infracción a la ley penal, en un sistema que se sustenta en la amplia discrecionalidad de las medidas educativas dispuestas mediante amplios mecanismos de control social no judicializados pero con incidencia estatal. La autora analiza la presencia de este modelo desjudicializador entre los años 40 y mediados de los años 70 en algunas legislaciones como la estadounidense con sus programas de diversion (desjudicialización) y en los Países Nórdicos caracterizados por un amplio sistema de protección social. Sin embargo, el modelo de la rehabilitación comienza a ser cuestionado a fines de los años sesenta con el argumento de la segregación de las clases sociales más desfavorecidas en las instituciones de educación social y la mayor incidencia de la trasgresión adolescente en el marco del incremento de medidas de desprotección social en Estados Unidos y Europa (2010: 132-134).

Respecto al mismo período, pero haciendo referencia al modelo penal de adultos, otros autores han elaborado un discurso respecto al auge de la criminología en el marco de los Estados de bienestar europeos y norteamericanos (CORNELLI, 2012). Con un discurso sustentado en la resocialización y el correccionalismo de los sectores excluidos de la producción de la riqueza en el contexto del auge del Estado de bienestar europeo con la socialdemocracia en el poder, la «criminología moderna» se constituyó como disciplina académica con reconocimiento social en Estados Unidos y Gran Bretaña, contando con apoyo estatal para sus investigaciones.

estudios demográficos e inversión del Estado en educación, salud y políticas sociales en perspectiva comparada, lo que da cuenta de un paulatino proceso de infantilización de la pobreza hasta el año 2005 que no ha logrado revertirse a pesar del incremento de la inversión social en los últimos diez años (DE ARMAS, 2006,2008) 
Los criminólogos académicos constituían entonces una voz valorada en el asesoramiento de las políticas criminales y en la opinión pública, convocados por los medios masivos de comunicación cuando aparecían situaciones de alerta social. El estudio del control social de los trasgresores gozaba entonces de popularidad en las universidades y la demanda de formación en la materia parecía incrementarse cada vez más. No obstante, con la aceleración de las transformaciones de la modernidad tardía, sumado a las políticas económicas de libre mercado, regresivas en materia de bienestar social y conservadoras en el plano cultural de finales de la década del setenta y en la década del ochenta, el asesoramiento en política criminal deja de ser demandado, los criminólogos se quedan sin trabajo y los estudios criminológicos se vuelven "más reflexivos, más críticos y más teoréticos" (GARLAND y SPARKS, 2000).

De acuerdo al análisis de González Tascón, a finales de la década del 70 y durante los años 80 surge el modelo de la responsabilidad o de la justicia en el contexto del "discurso neoliberal dirigido a la implantación de un nuevo proyecto social, basado en la transformación del Estado social y en la idea de «ley y orden» en un contexto de aumento de la inseguridad ciudadana” (2010: 134). En el marco de la desprotección social creciente de la población juvenil, con disminución de los indicadores de bienestar social y en un contexto de críticas hacia un modelo que extiende el control social hacia poblaciones cada vez más jóvenes, por trasgresiones más leves y sin garantías procesales y cuestionando modelos permisivos de educación social que se entendieron como excesivamente flexibles, el modelo de responsabilidad se sostiene en la concepción clásica del delito como producto de la libertad humana con la idea de culpabilidad asociada, que incluye también a los menores de edad (CABEZAS SALMERÓN,2011)

Se trata de un modelo de justicia que se sustenta en una sanción con contenido educativo "que acentúa la responsabilidad del menor mediante una medida «responsabilizadora» que le enfrente con el sentido de desvalor social de su comportamiento" (GONZÁLEZ TASCÓN, 2010: 135). De hecho este paradigma acerca la justicia penal juvenil al derecho penal adulto mediante una sanción que confunde con educación social reconociéndole tanto derechos sustantivos como procesales. "Esta propuesta de corte garantista y contenido esencialmente educativo se ha ido perfilando en los diversos textos internacionales que proliferaron en aquellos años en Naciones Unidas y en el Consejo de Europa” (2010: 135). En el marco de las Naciones Unidas es posible referenciar, con posterioridad a la Declaración Universal de los Derechos del Niño (1959), las Reglas Mínimas de las Naciones Unidas para la Administración de la Justicia Juvenil (Reglas de Beijing) de 1985, la Convención Internacional de los Derechos del Niño (1989), las Reglas Mínimas de las Naciones Unidas para los Jóvenes Privados de Libertad (1990) y las Directrices de las Naciones Unidas para la Prevención de la Delincuencia Juvenil (Directrices de Riadh) (1990), las Reglas Mínimas de las Naciones Unidas sobre las Medidas No 
Privativas de Libertad (Reglas de Tokio) (1990) y las Directrices de Acción sobre el Niño en el Sistema de Justicia Penal del Consejo Económico y Social (1997).

Estos textos proponen como criterio para los Estados la fijación de una edad mínima para la intervención penal en consonancia con el desarrollo físico, psíquico y emocional de los adolescentes, "si bien se puede observar como los legisladores tienen presentes también necesidades de política criminal de índole diversa”, anota la autora (2010: 136). Las edades mínima y máxima de responsabilización penal varían en función de cada Estado que suscribe los acuerdos internacionales en función de criterios como la sensación de inseguridad percibida en las sociedades y la percepción social de impunidad de las trasgresiones adolescentes. Con respecto a la edad máxima de actuación de la justicia juvenil las Directrices de Riadh establecen la posibilidad de considerar la categoría de adulto joven, recomendación que ha sido tomada en el caso de Alemania que fija en 21 años la edad máxima para ser considerado dentro del sistema de justicia juvenil. ${ }^{3}$

Aunque el modelo de responsabilidad o de justicia -que combina objetivos educativos con los principios del sistema penal- ha sido favorablemente acogido en la mayoría de los países, ha sido cuestionado por su identificación del tratamiento judicial de los adolescentes al sistema penal adulto, con el consiguiente endurecimiento del sistema de castigo que lo acerca más a un sistema en el que prima el objetivo de defensa social que de la protección de la infancia-adolescencia (GARCÍA PÉREZ, 1999 apud GONZÁLEZ TASCÓN, 2010: 140-141).

En el marco de este modelo de justicia también es posible identificar el movimiento de desjudicialización, despenalización, desinstitucionalización en correspondencia con el debido proceso surgido en Estados Unidos que lo diferencia por su tendencia a adoptar mecanismos procesales que tienden a limitar la introducción del adolescente en el sistema de justicia penal mediante una serie de procedimientos como el aumento de la edad de imputabilidad penal, la no persecución de determinadas conductas indeseables de menor jerarquía y la creación de circunstancias especiales que eximiría a los adolescentes de responsabilidad penal y de castigo.

El cuestionamiento al modelo de castigo de la justicia penal juvenil ha dado lugar a pensar en un nuevo modelo que supone una forma "más constructiva" de resolver los conflictos entre las partes denominado justicia restauradora. Este modelo plantea una nueva forma de considerar la trasgresión normativa, la relación entre la víctima o el ofendido por el acto y el ofensor, la propia comunidad y el Estado. En este sentido la víctima adquiere mayor protagonismo llamada a participar junto con el ofensor en la restauración del daño tanto material como simbólico. En relación a los ofensores se pretende enfrentarlos con el hecho cometido y sus consecuencias en

\footnotetext{
${ }^{3}$ No obstante las restricciones que impone la legislación alemana a la consideración de esta categoría y las voces que se han levantado en contra demandando mayor punición -siguiendo las demandas punitivas del resto de Europa-, la mayoría de los especialistas consideran la importancia de mantener esta franja etárea del adulto joven para la consideración de ciertas infracciones que incluso puede llegar a los 24 años de edad (GONZÁLEZ TASCÓN, 2010: 157-158).
} 
relación a las víctimas en un proceso que favorece su reinserción social a partir de la asunción de su responsabilidad en la infracción (GIMÉNEZ-SALINAS, 1996; GONZÁLEZ TASCÓN, 2010; GONZÁLEZ PILLADO, 2012; COLOMER HERNÁNDEZ, 2012).

El Estado limita su participación en beneficio de la comunidad y de los directamente afectados en la resolución del conflicto. Este modelo fue acogido por primera vez en la legislación de Nueva Zelanda en 1989 con la aprobación de la Children, Young Persons and their Families Act y ha sido replicado formalmente en la legislación de Irlanda del Norte en 2002. En otros países europeos, el modelo fue introducido informalmente mediante el influjo de académicos, profesionales del derecho y trabajadores sociales, recibiendo en algunos casos el respaldo en la legislación ${ }^{4} y$ en otros quedando como una forma de resolución de conflictos de carácter residual que trata de evitar su judicialización (GONZÁLEZTASCÓN, 2010).

\section{EL DEBATE EN LA PRÁCTICA DE LA IMPLEMENTACIÓN DE LA JU STICIA RESTAURATIVA}

En el derecho penal adulto, la reparación se considera una acción de carácter simbólico realizada por el infractor " (presentación de disculpas), económico (restitutorio, compensatorio o indemnizatorio) o material (prestación de un servicio) en favor de la víctima (individual o colectiva)” (LARRAURI, 1997: 172).

La autora reconoce tres influencias en el advenimiento de la justicia restaurativa como «sanción penal autónoma» alternativa a la pena de privación de libertad: i) el impacto de la victimología de los años 80 (que surge en respuesta a la criminología crítica con la percepción de su énfasis en los derechos del infractor, ésta recupera los derechos de la víctima); (ii) el modelo resocializador que pretende evitar los efectos desocializadores de la privación de libertad en un modelo de confrontación del trasgresor y la víctima ${ }^{5} \mathrm{y}$ (iii) la influencia del abolicionismo penal desde el modelo que propone Nils Christie. Habiendo olvidado el papel de los protagonistas del conflicto, Christie plantea que el Estado lo expropia en el sistema de justicia penal proponiendo su recuperación mediante el diálogo de las partes en pos de acuerdos restauradores (1992) .

\footnotetext{
${ }^{4}$ El modelo actúa mediante la convocatoria a reuniones familiares por un trabajador social en las que participa el ofensor, su familia $\mathrm{u}$ otras personas invitadas interesadas en su bienestar, el ofendido o su representante con su familia u organizaciones y personas de apoyo y en los casos en que el conflicto haya sido judicializado la policía y el defensor del adolescente. Las reuniones son coordinadas por el trabajador social que intenta buscar el acuerdo en beneficio de las partes y de la comunidad. La celebración de estas reuniones parte del supuesto del reconocimiento de la responsabilidad del ofensor en el acto que se le atribuye (GONZÁLEZ TASCÓN, 2010).

${ }^{5}$ Matellanes reconoce las mismas influencias en la justicia restaurativa que Larrauri incluyendo la discusión del fracaso del modelo resocializador (2011).

${ }^{6}$ El momento de auge de la justicia restaurativa es atribuido tanto por LARRAURI (1997) como por MATELLANES (2011) al artículo de Nils CHRISTIE Conflicts as property, publicado en 1977 en British Journal of Criminology, 17 que fuera traducido posteriormente en un volumen publicado por la editorial argentina Ad Hoc en 1992 bajo el título ¿De quién son los conflictos? que es la referencia que se utiliza en esteartículo.
} 
Desde ésta última perspectiva, la autora define la reparación como un formato de justicia que "compensa (en vez de castiga), reintegra (en vez de excluye) y media (en vez de impone) " (LARRAURI, 1997: 173). El sistema de reparación y con sus mecanismos de mediación han sido vistos con buenos ojos, aun en casos de trasgresiones socialmente más condenables, con algunas excepciones como en las situaciones en los que la víctima prefiere no confrontar con el ofensor o se encuentra en inferioridad de condiciones (CHRISTIE, 2001)

Sin pretender sintetizar el debate jurídico que la mediación, como instrumento privilegiado de la justicia restaurativa ha suscitado entre los especialistas, corresponde destacar las objeciones más destacadas para las que Matellanes propone tomar ciertas cautelas:

1. La idoneidad del mediador que requiere de calificación en una tarea que se pretende objetiva, imparcial y cercana aunque no directamente implicada;

2. La necesidad de proporcionar información a las partes implicadas acerca del proceso y sus consecuencias ${ }^{7}$;

3. La salvaguarda de los principios de igualdad y proporcionalidad, difíciles de establecer dado que cada proceso puede dar lugar a soluciones distintas en conflictos similares, a lo que se suma el cuestionamiento del principio de legalidad, dado que las conductas reprochables requieren de tipificación previa;

4. La implicación del respeto al principio de inocencia de la persona que decide voluntariamente suscribir un acuerdo de mediación, así como el riesgo de que el ofensor sea sometido a condicionamientos excesivos por el lugar subordinado en que se encuentra (2011).

Frente a estas objeciones, los defensores de la mediación responden que el respeto a los principios en cuestión queda a salvo siempre que se actúe en un marco de legalidad regulado. Por ejemplo, el principio de proporcionalidad o la sospecha de respuestas excesivas en el contexto de la mediación pueden evitarse estableciendo máximos posibles y supervisando judicialmente los acuerdos alcanzados. Para respetar el principio de inocencia es posible establecer la imposibilidad de declaración del mediador como testigo en un posible juicio o que se registren por escrito exclusivamente los acuerdos alcanzados, evitando toda posible referencia a los actos reconocidos por el infractor. En este sentido se destaca, en oposición a la privatización del conflicto propuesto por Christie en su primer planteamiento, la declaración de respeto a la legalidad y a la regulación procesal y a las garantías de todos los implicados en el marco del sistema judicial (MATELLANES, 2011).

La objeción más atendible refiere al tipo de conductas pasibles de ser respondidas mediante un proceso de mediación, dado que, si el procedimiento solo refiere a las infracciones menores, es posible suponer una extensión del control social formal a conductas que anteriormente no hubieran sido objeto de intervención

\footnotetext{
${ }^{7}$ Larrauri anota que la mediación no es posible en caso de que alguna de las partes no comprenda el proceso(2004).
} 
judicial. Asimismo resulta pertinente el planteamiento de la inadecuación del sistema de mediación en los casos de los llamados «delitos sin víctima» o cuando las víctimas son difusas. Lo mismo ocurre cuando las ofensas son producidas por organizaciones poderosas en donde la víctima tiene muy escaso margen de negociación en un proceso de mediación sin asistencia legal. Se destaca también la prohibición de la utilización del procedimiento de mediación en las agresiones que suponen violencia de género en la regulación española de 2004 (MATELLANES, 2011).

A estas objeciones se han sumado los debates en relación al regreso de la víctima en los procesos judiciales con posiciones que tienen a considerar esta vuelta como un retorno a un modelo de vindicación y venganza de carácter conservador, como las que abogan por su participación en las decisiones que les competen (sin pretensión de exhaustividad ya que la bibliografía sobre el tema excede ampliamente los intereses de esta exposición se mencionan como referencias BUSTOS y LARRAURI, 1993; ALBRECHT, 1999; GARLAND, 2005).

En su análisis sobre el proceso de informalización del derecho penal que ha venido tomando forma en Alemania y otros países occidentales, Albrecht enuncia un discurso crítico que permite visualizar el significativo aumento de la participación de la víctima en los procesos penales, aportando pruebas a la fiscalía que no siempre son recuperadas de acuerdo a los procedimientos formales establecidos en detrimento de las garantías del ofensor. En este proceso de «privatización de la seguridad pública» el autor enumera el aumento de los sistemas de seguridad privados que custodian espacios públicos y la privatización de los servicios penitenciarios que ponen en tela de juicio la celebración de la recuperación del conflicto de la víctima y el ofensor (1999).

Albrecht (1999) habla de una "funcionalización del papel de la víctima con fines políticos" más que de la recuperación del conflicto y del carácter conciliador en la participación de los involucrados mediante estrategias de reparación social que ven otros analistas como MATELLANES, (2011) GONZÁLEZ TASCÓN, (2010) GONZÁLEZ PILLADO (2012), COLOMER HERNÁNDEZ, (2012) o GIMÉNEZ-SALINAS (1996). Sin embargo, estos autores observan que la legitimación del acto de mediación debe estar regulada en el plano legislativo y controlada judicialmente para evitar la privatización del sistemajudicial.

Considerando los cambios legislativos y de ejecución penal en Estados Unidos y Europa con el endurecimiento de la pretensión punitiva del Estado y la alarma provocada por la colocación de la seguridad pública en la primera plana de la agenda política, las posturas a favor de la justicia restaurativa han quedado reducida a la represión de ofensas menores y faltas que anteriormente no habrían sido objeto de persecución penal (ALBRECHT, 1999). El peligro, como observa Larrauri es que estos instrumentos constituyan una 
extensión del control social para las infracciones consideradas más leves y no configuren una alternativa real a la privación de libertad. ${ }^{8}$

Particularmente significativa por el movimiento de la justicia restaurativa ha sido considerada para la aplicación del sistema de mediación en la justicia juvenil por sus potencialidades en la resolución dialogada de conflictos en una etapa de formación en la vida del niño y el adolescente (AYORA MASCARELL, 1997). No obstante, su utilización continúa siendo marginal en la mayor parte de los países europeos, siendo utilizada en casos de infracciones leves e incluso en faltas que no configurarían una figura tipificada penalmente en el caso de adultos, cuya regulación no ha sido institucionalizada a es aplicada en casos muy específicos y determinadas condiciones preestablecidas por las legislaciones nacionales (GONZÁLEZ TASCÓN,2010).

\section{EL CUESTIONAMIENTO DEL MODELO DE LA RESPONSABILIDAD DE LOS TRATADOS INTERNACIONALES EN LA JUSTICIA JUVENIL POR LA INFLACIÓN LEGISLATIVA DE PROPUESTAS PUNITIVAS EN URUGUAY Y ESPAÑA.}

En el marco de la Convención Internacional de los Derechos del Niño (1989), los países europeos y latinoamericanos han establecido legislaciones nacionales orientadas en el espíritu del nuevo modelo de justicia, respetuoso de las garantías procesales de los adolescentes en el marco de las regulaciones penales dispuestas en la materia. La aprobación de los distintos códigos nacionales en Latinoamérica ha sido expuesta en distintos trabajos que analizan pormenorizadamente el contexto nacional e internacional de surgimiento (GARCÍA MÉNDEZ y CARRANZA, 1990, 1993; GARCÍA MÉNDEZ, 1994, 2007; BELOFF, 1994, 2004, 2005; BELOFF y GARCÍA MÉNDEZ, 1998; DÁVILA y NAYA, 2010). Partiendo de este contexto internacional interesa ahora recorrer la discusión legislativa y social que se ha dado luego de la aprobación de este tipo de legislación nacional en España y en Uruguay analizando las modificaciones regresivas en materia legislativa producidas luego de la celebración de las primeras modificaciones realizadas en sintonía con las recomendaciones internacionales.

En España, el proceso legislativo puede seguirse desde el advenimiento de la democracia en un tortuoso proceso que culmina con la aprobación de la Ley Orgánica 5/2000 del 12 de enero que es recibida por los especialistas como un avance positivo en la materia y celebrado como producto de la adecuación de la normativa nacional a los compromisos internacionales.

\footnotetext{
${ }^{8}$ Larrauri (1997) argumenta extensamente acerca de la posibilidad de utilizar la justicia restaurativa como «sanción penal autónoma» alternativa a la pena privativa de libertad y no, como exponen otros analistas, como una adición o consecuencia civil al castigo penal.
} 
En Uruguay, por su parte, la adecuación legislativa con los compromisos internacionales se concreta con la aprobación del Código de la Niñez y la Adolescencia (Ley 17.823) del 14 de setiembre de 2004 después de un largo proceso de discusión parlamentaria.

No obstante el avance que suponen las legislaciones de ambos países en sintonía con el modelo de justica juvenil aprobado por los organismos internacionales, en ambos países se han producido una serie de modificaciones legislativas, al amparo de las demandas sociales de mayor represión que, tomadas por el populismo político han endurecido los procedimientos penales en detrimento de las garantías y la protección de los ofensores (MORILLAS CUEVA, 2010; GONZÁLEZ LAURINO,2015).

En España, la Ley Orgánica 5/2000 fue publicada en el Boletín Oficial del Estado (BOE) el día 13 de enero del 2000, pero establece un período de un año para su entrada en vigencia que se hizo efectivo el 13 de enero de 2001. En el período que va desde su aprobación hasta su vigencia fue modificada por la Ley Orgánica 7/2000, que junto a otros cambios de la legislación en materia penal, establece una disposición específica que endurece las sanciones privativas de libertad para los adolescentes involucrados en infracciones a la ley penal tipificadas como terrorismo, en sintonía con los reclamos de la población en aquel contexto. Se dispone que esta ley entre en vigor al día siguiente de su publicación oficial, el 24 de diciembre de 2000, con excepción del artículo dispuesto para los adolescentes que entra en vigencia el mismo día en que lo hace la Ley Orgánica 5/2000. ${ }^{9}$

La segunda modificación de la Ley Orgánica 5/2000 antes de su entrada en vigor está relacionada con el aplazamiento de la entrada en vigor de la disposición relativa a los mayores de 18 años y menores de 21 años por el término de dos años, de acuerdo a la Ley Orgánica 9/2000 que entró en vigencia al día siguiente de su publicación oficial el 23 de diciembre de 2000.

Con el antecedente de las Disposiciones finales de la LO 15/2003 que modifica la LO 10/1995 del Código Penal y la LO 5/2000, introduciendo a la víctima en el proceso penal y dictaminando un endurecimiento de medidas punitivas en caso de algunas ofensas que involucran a los adolescentes, se llega a la aprobación de la LO 8/2006 del 4 de diciembre que modifica nuevamente la LO 5/2000 promoviendo una serie de medidas que suponen un significativo aumento en la punición de los adolescentes entre 14 y 16 años ${ }^{10}$ y el cumplimiento de

\footnotetext{
${ }^{9}$ Asimismo excluye de la aplicación del Artículo 4 de esta ley a los mayores de 18 años y menores de 21 (que incluyera en sintonía con disposiciones similares a la legislación alemana en la categoría de joven adulto) para los casos de las infracciones a la ley penal tipificados como homicidio, asesinato, agresiones sexuales, terrorismo y todas aquellas que el Código Penal sancionara con penas de prisión igual o superior a quince años. En los adolescentes entre 14 y 16 años aumenta la privación de libertad de uno a ocho años y la libertad vigilada posterior en las casos de más de una infracción, en infracciones consideradas graves o en las tipificadas como terrorismo, en cuyo caso la privación de libertad puede llegar hasta diez años para los mayores de 16 años y cinco años para los adolescentes entre 14 y 16 años de edad.

${ }^{10}$ Estas medidas suponen una ampliación de los supuestos por los cuales imponer medidas de privación en régimen cerrado (infracciones graves, infracciones menos graves en los que se actuare con violencia o cualquier infracción en los que se actuare colectivamente), modificación del tiempo de duración de las medidas en relación a la edad y al tipo de infracción, aumento de la duración de la medida cautelar en régimen de internación, creación de una medida cautelar que dispone el alejamiento de la _vol.09, nº. 02, Rio de Janeiro, 2016. pp. 652-669 
las medidas de privación de libertad para los mayores de 18 y menores de 21 años en el sistema penal de adultos ${ }^{11}$. La nueva ley entra en vigencia el 5 de febrero de 2007. (DE LA ROSA CORTINA, 2007; CARMONA SALGADO, 2008; MORILLAS CUEVA, 2010)

En Uruguay el debate social en torno a la inseguridad pública se ha centrado en la infracción adolescente en los últimos cinco años con reclamos punitivos por parte de los principales partidos políticos de oposición, encabezados por el Partido Colorado que ha presentado un proyecto legislativo de modificación de la edad de imputabilidad penal de 18 a 16 años, plebiscitado el 24 de octubre de 2014 junto con las eleccionesnacionales.

En este contexto de movilizaciones sociales y políticas a favor y en contra del proyecto parlamentario presentado, el legislativo, con apoyo de todos los partidos políticos, ha generado un conjunto de leyes que suponen la inflación penal modificando el Código de la Niñez y la Adolescencia (2004).

En primer lugar, la Ley 18.777, publicada en el Diario Oficial el 11 de agosto de 2011, sanciona con medida de privación de libertad la tentativa de hurto lo que produce un aumento en la cantidad de adolescentes internados.

En segundo término, la Ley 18.778, publicada en el Diario Oficial el 11 de agosto de 2011, mantiene el registro de los antecedentes penales de los adolescentes después de cumplidos los 18 años de edad, de manera que se posibilite imputar su conducta como agravante al juzgar la infracción del adulto.

En tercer lugar, la Ley 19.055, publicada en el Diario Oficial el 22 de enero de 2013, establece como mínimo los doce meses de privación de libertad para las infracciones que la misma ley define como "gravísimas" en adolescentes entre 15 y 18 años de edad.

Así, tanto la Ley Orgánica 5/2000 en España, como el Código de la Niñez y la Adolescencia en Uruguay (2004) que, pese a los cuestionamientos recibidos, fueron consideradas legislaciones progresistas en la materia de justicia juvenil por los especialistas, han sufrido una serie de modificaciones legislativas inspiradas en el establecimiento de medidas más punitivas para los adolescentes judicializados. Estas transformaciones legislativas, procesadas durante gobiernos y parlamentos con mayorías de izquierda, se enmarcan en procesos de cambios sociales más profundos en los que la seguridad pública pasa a ser una demanda «popular», "en el sentido fuerte de la expresión”, al decir de Robert Castel (2004). Resulta paradojal que la infracción adolescente, subrepresentada en relación a la protagonizada por adultos en términos estadísticos en ambos países, constituya el foco de atención

víctima, de su familia o cualquier otra persona que el juez determine y fortalecimiento de medidas de protección a las víctimas. Las disposiciones referidas a las víctimas son consideradas positivas por los analistas más críticos de esta legislación.

${ }^{11}$ Se genera la supresión definitiva de la posibilidad de aplicar la LO 5/2000 a los jóvenes entre 18 y 21 años. La mención a la fecha de vigencia de la LO 8/2006 resulta significativa para los analistas dado que, de la posibilidad de aplicación del Artículo 4 de la LO $5 / 2000$ a los adultos jóvenes estuvo en vigencia del 1 de enero al 5 de febrero de 2007 debido a un error de cálculo de los legisladores que suspendieron su vigencia mediante la LO 7/2000. 
de las demandas represivas por parte de los sectores sociales más conservadores. Llama la atención también que los gobiernos socialdemócratas en el poder con mayoría parlamentaria se hagan eco de estos llamamientos al aumento de la punición juvenil en el plano legislativo y en la elaboración de políticas criminalizantes para este sector de la población que requiere de especial protección estatal en función de su mayor vulnerabilidad respecto a otros grupos sociales.

\section{CONSIDERACIONES FINALES}

Pese a que las críticas indican que el modelo de responsabilidad promueve un modelo de justicia que lo acerca al sistema penal de adultos mediante la promoción de prácticas educativas que constituyen una forma de castigo eufemizada, ha sido aceptado en las legislaciones de la mayoría de los países que suscriben los acuerdos internacionales. El modelo de justicia restaurativa, que entusiasma a algunos analistas y subleva a otros comienza a ser ensayado como alternativa a la judicialización en algunos países europeos, albergado por otros desde la legislación y el sistema de justicia y ensayado como experiencia piloto en Uruguay. El planteo de la advertencia que su práctica limitada a acciones consideradas faltas u ofensas menores podría suponer la extensión del sistema de control social a acciones que no serían punibles en el sistema judicial parece ser de recibo entre quienes apuestan por la limitación del sistema de castigo entre los integrantes más jóvenes de la sociedad.

Sin embargo, mientras avanza este debate sobre la mediación y la justicia restaurativa parece desarrollarse en paralelo el empuje de un sistema más restrictivo de los derechos y garantías de los adolescentes a impulsos de reclamos socio-políticos de incremento de la punitividad. Si bien hay quienes plantean como error la lectura que traslada las crecientes prácticas represoras en el sistema anglosajón — sobre todo desde Estados Unidos y Gran Bretaña - al modelo de justicia europeo, el análisis de las modificaciones a la legislación respecto a la infracción juvenil en España generada a partir de la LO 5/2000 parece mostrar esta tendencia. Lo mismo puede afirmarse de las propuestas de cambios al Código de la Niñez y la Adolescencia en Uruguay en los últimos años, algunas de las cuales han llegado a plasmarse en la legislación nacional.

Si bien el resultado del plebiscito en Uruguay, que puso a consideración de la ciudadanía el proyecto de ley de modificación de la Constitución y el Código de la Niñez y la Adolescencia para juzgar a los adolescentes de 16 años como adultos en octubre de 2014 puso coto al avance del modelo represivo por el momento, no resulta improbable que el avance del modelo punitivo haya cesado en sus intentos criminalizadores de este sector de la población. La reacción política a los problemas sociales y la influencia del espacio de la crónica policial en los medios de comunicación masiva ejerce una influencia considerable en el análisis de los cambios sociales producidos en la modernidad tardía, lo que lleva a analizar "como cuestiones de control social lo que no son sino problemas en la generación de bienestar social" (GARLAND y SPARKS, 2000: 199). 
La recuperación de la historia de los modelos de justicia que se han implementado en Estados Unidos, Europa y en América Latina dan cuenta de un proceso que coloca en el centro del debate del control social de los adolescentes. Como en los orígenes del paradigma tutelar, el avance de las explicaciones conservadoras en el plano social y cultural de la modernidad tardía ha provocado una modificación de la percepción social de los problemas sociales que tienen a incrementar el temor a sectores sociales excluidos de la producción de la riqueza que pasan a ser considerados "irresponsables y peligrosos" y por tanto "no merecedores" de apoyo social. El discurso de la «crisis de los valores», de «la pérdida de la centralidad de la familia como modelo de convivencia social» y de «la flexibilización de los límites paternos para con los más jóvenes» dan cuenta de un discurso regresivo en las políticas de protección social de los adolescentes. El modelo garantista de los derechos en el proceso judicial constituye sin dudas un avance frente al modelo de indiscriminación de abandono y delincuencia, pero no responde al problema de la justificación judicial de la internación como medida de protección social de los adolescentes más desamparados (GONZÁLEZ LAURINO,2013).

Pero si la práctica legislativa en Uruguay recuerda al modelo del juez tutelar no resultan menos preocupantes las políticas regresivas en materia de derechos juveniles desarrolladas en España y en Uruguay. Parecería que, como dice Garland, (2005) el populismo represivo en consonancia con las demandas sociales tienden a ser tomadas como referencias político-legislativas. Con especial cuidado deben tomarse las demandas de las víctimas y su incidencia en el proceso penal ya que, si bien resulta positiva su incorporación en procesos de resarcimiento y mediación para hacer comprensibles los condicionamientos sociales y las motivaciones del agresor en sus ofensas, la incorporación de la veta vindicativa y su participación en el proceso judicial de aportación de pruebas de la ofensa pueden resultar en una privatización del proceso penal que puede limitar las garantías de los acusados.

\section{MODELS OF JUVENILE CRIMINAL JUSTICE DEBATE IN THE EARLY TWENTY - FIRST CENTURY}

\section{Abstract}

The article presents a journey through the juvenile justice models developed throughout the history of contemporary thought to center the look on the accountability system promoted by international organizations and debate around the alternative proposed by restorativejustice.

Through a comparative analysis the repressive modifications processed in recent years in the Spanish and Uruguayan legislation implemented after its adaptation to international treaties signed by both countries at the beginning of the century are reviewed.

Attend the debate that arises around the model of restorative justice as an alternative to the prosecution of the youngest members of society of caring a type of practice limited to the transgressions under adolescents, which 
could involve the extension of the control social system actions that would not be punishable in the juvenile criminal justice model suggested by international governing bodies in thefield.

Keywords: models of juvenile justice, responsibility, childhood, adolescence, restorativejustice.

\section{BIBLIOGRAFÍA}

ALBRECHT, Peter-Alexis. "The Functionalization of the Victim in the Criminal Justice System", in Buffalo Criminal Law Review, 1999. 3: pp.91-107.

AYORA MASCARELL, Lidia. "Alternativas al internamiento en la jurisdicción de menores", en CID, José y LARRAURI, Elena (coords.) Penas alternativas a la prisión. Barcelona, Bosh. 1997, pp.251-275

BELOFF, Mary y GARCÍA MÉNDEZ, Emilio. Infancia, ley y democracia. Análisis crítico del panorama legislativo en el marco de la Convención Internacional de los Derechos del Niño (1990-1998). 1998, Bogotá, Temis-De Palma.

"De los delitos y de la infancia", en Nueva Sociedad, 129, enero-febrero, 1994, pp. 104-113.

Los derechos del niño en el sistema interamericano. 2004, Buenos Aires, Ediciones del Puerto.

"Los adolescentes y el sistema penal. Elementos para una discusión necesaria en la Argentina actual". Revista Jurídica de la Universidad de Palermo, 2005, pp.97-122.

BUSTOS RAMÍREZ, Juan y LARRAURI PIJOAN, Elena. Victimología: presente y futuro. Hacia un sistema penal de alternativas. Barcelona, PPU. 1993

CABEZAS SALMERÓN, Jordi. "Superación del modelo anterior de justicia juvenil (tutelar) por el actual modelo (de responsabilidad) ¿Se lo ha creído alguien?”, en Revista Crítica Penal y Poder, 2011, septiembre (1) pp. 158173.

CARMONA SALGADO, Concepción. "Algunas consideraciones críticas sobre las sucesivas reformas de la legislación penal de menores a partir de la LO 5/2000. La nueva Ley 8/2006”, en La ley penal: revista de derecho penal, procesal y penitenciario, 45, 2008, pp. 57-65.

CASTEL, Robert. La inseguridad social. ¿Qué es estar protegido? Buenos Aires, Manantial.2004

CHRISTIE, Nils. "Los conflictos como pertenencia”, en MAIER, Julio (comp.) De los delitos y de las víctimas. Buenos Aires, Ad Hoc. 1992.

"Answers to Atrocities: Restorative Justice in Extreme Situations", in E. Fattah \& S. Parmentier (eds.) Victim Policies and Criminal Justice on the Road to Restorative Justice. Leuven, Leuven University Press. 2001. pp.379-392.

COLOMER HERNÁNDEZ, Ignacio. "La mediación penal con menores infractores en la LORPM", en GONZÁLEZ PILLADO, Esther (coord.) (2012) Mediación con menores infractores en España y los países de su entorno. Valencia, Tirant lo Blanch, Monografías, 805. 2012. pp. 89-127.

CORNELLI, Roberto. Miedo, criminalidad y orden. Buenos Aires-Montevideo, B de F.2012. 
DAROQUI y LÓPEZ. “Contextos socio-históricos en la construcción y gobierno de «la minoridad»”, en DAROQUI, Alcira, LÓPEZ, Ana Laura y CIPRIANO GARCÍA, Roberto (eds.) Sujeto de castigos. Hacia una sociología de la penalidad juvenil. Buenos Aires, Homo Sapinens, 2012. pp.49-59.

DÁVILA, Paulí y NAYA, Luis María. "Infancia, educación y Códigos de la Niñez en América Latina. Un análisis comparado", en Revista Española De Educación Comparada, (16), 2010. pp. 213-233. Retrieved from http://search.proquest.com/docview/1138783986?accountid=14777

DE ARMAS, Gustavo. "Sociedad y políticas sociales en Uruguay desde la transición democrática al gobierno del Frente Amplio”, en: América Latina Hoy, vol. 44, diciembre, 2006, pp. 41-61 Universidad deSalamanca

DE ARMAS, Gustavo. Reflexiones sobre la "Estrategia Nacional para la Infancia y Adolescencia” y el modelo de desarrollo de Uruguay hacia el año 2030, en Sustentabilidad Social. Estrategia Nacional para la Infancia y Adolescencia, ENIA 2010-2030. Montevideo.2008.

DE LA ROSA CORTINA, José Miguel. "Novedades en el sistema de justicia juvenil sobre las medidas imponibles y sus reglas de determinación", en La ley penal: revista de derecho penal, procesal y penitenciario, 36, 2007.pp. 48-68.

GARCÍA MÉNDEZ, Emilio y CARRANZA, Elías. Infancia, Adolescencia y Control Social en América Latina, Buenos Aires, Depalma. 1990.

Del revés al derecho: la condición jurídica de la infancia en América Latina: bases para una reforma legislativa. UNICEF, UNICRI, ILANUD. Buenos Aires, Galerna. 1993.

"La Convención Internacional de los Derechos del Niño: del menor como sujeto de compasiónrepresión a la infancia-adolescencia como sujeto de derechos", en Derecho de la infancia/adolescencia en América Latina: de la situación irregular a la protección integral. Ed. Forum-Pacis, Bogotá. 1994.

"Infancia, ley y democracia: una cuestión de justicia", en Justicia y Derechos del Niño, 9, pp. 27-47. UNICEF. Santiago, Chile. 2007.

GARLAND, David y SPARKS, Richard. "Criminology, Social Theory and the Challenge of Our Times", in British Journal of Criminology. Special Issue: Criminology and Social Theory, 40, (2), 2000. pp. 189-204.

GARLAND, David. La cultura del control. Crimen y orden social en la sociedad contemporánea. Barcelona, Gedisa. 2005.

GIMÉNEZ-SALINAS COLOMER, Esther. "La mediación en el sistema de justicia juvenil: una visión desde el derecho comparado”, en Menores privados de libertad, Cuadernos de Derecho Judicial. Madrid, Escuela Judicial - Consejo General del Poder Judicial. 1996.

GONZÁLEZ LAURINO, Carolina. Los discursos expertos sobre la responsabilidad en la infracción adolescente. Montevideo, CSIC, Udelar. 2013.

"La infracción adolescente a la ley penal en el centro del debate sobre seguridad pública en Uruguay", en Revista Latinoamericana de Ciencias Sociales, Niñez y Juventud, 13 (2) julio-diciembre 2015. pp.951-962.

GONZÁLEZ PILLADO, Esther. "La mediación como manifestación del principio de oportunidad en la Ley de Responsabilidad de Menores”, en GONZÁLEZ PILLADO, Esther (coord.). (2012) Mediación con menores infractores en España y los países de su entorno. Valencia, Tirant lo Blanch, Monografías, 805. 2012. pp.53-87. 
Mediación con menores infractores en España y los países de su entorno. Valencia, Tirant lo Blanch, Monografías, 805.Valoraciones y representaciones sobre la ley y la administración de justicia, en Revista Crítica PenalyPoder, 8,2012.pp. $18-46$.

GONZÁLEZ TASCÓN, María Marta. El tratamiento de la delincuencia juvenil en la Unión Europea. Hacia una futura política común. Valladolid, Lex No. 2010.

GUEMUREMAN, Silvia. "La justicia de menores desde la mirada de los jueces. Valoraciones y representaciones sobre la ley y la administración de justicia, en Revista Crítica Penal y Poder, 2015, (8). Marzo, pp. 18-46.

LARRAURI PIJOAN, Elena. “La reparación”, en CID MOLINÉ, José y LARRAURI PIJOAN, Elena (coord.) Penas alternativas a la prisión. Barcelona, BOSH Casa Editorial. 1997.

"Tendencias actuales de la justicia restauradora", en Serta. In memoriam A. Baratta. Salamanca, Ediciones Universidad de Salamanca, Pérez Álvarez Editor. 2004.

LEOPOLD COSTÁBILE, Sandra. Los laberintos de la infancia. Discursos, representaciones y crítica. Montevideo, CSIC-Udelar. 2013.

Ley 18.777. Publicada en el Diario Oficial el 11/08/2011. Recuperado de http://www.parlamento.gub.uy/leyes/AccesoTextoLey.asp?Ley=18777yAnchor

Ley 18.778. Publicada en el Diario Oficial el 11/08/2011 Recuperado de http://www.parlamento.gub.uy/leyes/AccesoTextoLey.asp?Ley=18778yAnchor

Ley 19.055. Publicada en el Diario Oficial el 22/01/2013. Recuperado de http://www.parlamento.gub.uy/leyes/AccesoTextoLey.asp?Ley=19055yAnchor

Ley Orgánica 15/2003 de 25 de noviembre por la que se modifica la Ley Orgánica 10/1995 de 23 de noviembre del Código Penal. Publicada en el Boletín Oficial del Estado número 283 el 26 de noviembre de 2003. Recuperado de: http://www.boe.es/boe/dias/2003/11/26/pdfs/A41842-41875.pdf el 4 de julio de2015.

Ley Orgánica 5/2000 de 12 de enero, Reguladora de la Responsabilidad Penal de los Menores. Publicada en el Boletín Oficial del Estado número 11 el 13 de enero de 2000. Entrada en vigor el 13 de enero de 2001. Recuperado de: http://www.boe.es/buscar/act.php?id=BOE-A-2000-641 el 4 de julio de2015.

Ley Orgánica 7/2000 de 22 de diciembre de modificación de la Ley Orgánica 10/1995 de 23 de noviembre del Código Penal y de la Ley Orgánica 5/2000 de 12 de enero, Reguladora de la Responsabilidad penal de los Menores, en relación con los delitos de terrorismo. Publicada en el Boletín Oficial del Estado 307 el 23 de diciembre de 2000. Recuperado de: http://www.boe.es/boe/dias/2000/12/23/pdfs/A45503-45508.pdf el 4 de julio de 2015.

Ley Orgánica 8/2006 del 4 de diciembre por la que se modifica la Ley Orgánica 5/2000 de 12 de enero, Reguladora de la Responsabilidad penal de los Menores. Publicada en el Boletín Oficial del Estado número 290 el 5 de diciembre de 2006. Recuperado de: http://www.boe.es/boe/dias/2006/12/05/pdfs/A4270042712.pdf el 4 de julio de 2015.

Ley Orgánica 9/2000 de 22 de diciembre sobre medidas urgentes para la Agilización de la Administración de Justicia por la que se modifica la Ley Orgánica 6/1985 de 1 de julio del Poder Judicial. Publicado en el Boletín 
Oficial del Estado 307 el 23 de diciembre de 2000. Recuperado de: http://www.boe.es/boe/dias/2000/12/23/pdfs/A45522-45526.pdf el 4 de julio de2015.

MATELLANES RODRÍGUEZ, Nuria. "La justicia restaurativa en el sistema penal. Reflexiones sobre la mediación”, en DIZ, Fernando Martín (coord.) La mediación en materia de familia y derecho penal. Estudios y análisis. Santiago de Compostela, Andavita Editora.2011.

MORILLAS CUEVAS, Lorenzo. "La política criminal de menores como expresión de una continuada contradicción”, en BENÍTEZ ORTÚZAR, Ignacio y CRUZ BLANCA, María José (coords.) El Derecho Penal de Menores a debate. I Congreso Nacional sobre Justicia Penal Juvenil. Madrid, Universidad de Jaen - Dykinson. 2010. pp. 15-52.

PLATT, Anthony. Los "Salvadores del Niño" o la invención de la delincuencia. México, Siglo XXI. 1982.

THERBORN, G. "Los derechos de los niños desde la constitución del concepto de menor. Un estudio comparado de países occidentales", en Intercambio Social y Desarrollo del Bienestar, MORENO, Luis (comp.), Consejo Superior de Investigaciones Científicas, Instituto de Estudios Sociales Avanzados, Madrid. 1993. pp. 77 143.

\section{BIBLIOGRAFÍA COMPLEMENTARIA SOBRE JU STICIA RESTAURATIVA Y MEDIACIÓN}

BRAITHWAITE, John (1996). Restorative Justice and a Better Future Dorothy J. Killam Memorial Lecture. Dalhousie University, October 17.

CRAWFORD, Adam and Newburn, Tim (2003). Youth Offending and Restorative Justice: Implementing Reform in Youth Justice Devon, UK: Willan Publishing.

DIGNAN, James (2005). Understanding Victims and Restorative Justice Maidenhead, England: Open University Press

MARSHALL, Christopher D. (2001). Beyond Retribution: A New Testament Vision for Justice, Crime, and Punishment Grand Rapids: Wm. B. Eerdman's Publishing Company.

NEWBURN, Tim, ed (2013) Criminology 2nd, Routledge, Abingdon, UK.

Trabalhoenviadoem03 deagostode2015.

Aceitoem04denovembrode2015. 